\title{
STUDYING THE THERMAL BEHAVIOUR OF CONCRETE STRUCTURE USING NANOENCAPSULATED PHASE CHANGE MATERIALS
}

\author{
Deepak Raja $V^{1}$, Harsha Vardhana Balaji ${ }^{2}$, Karthikeyan $M^{3}$, $\operatorname{Narmadha~} N^{4}$, Visagavel $K^{5}$ \\ ${ }^{1} P G$ Scholar, Department of Mechanical Engineering, Knowledge Institute of Technology, Tamilnadu, India \\ ${ }^{2}$ Assistant Professor, Department of Civil Engineering, Knowledge Institute of Technology, Tamilnadu, India \\ ${ }^{3}$ Assistant Professor, Department of HSE, University of Petroleum and Energy Studies, Dehradun, India \\ ${ }^{4}$ Assistant Professor, Department of Mechanical Engineering, Knowledge Institute of Technology, Tamilnadu, India \\ ${ }^{5}$ Professor, Department of Mechanical Engineering, Knowledge Institute of Technology, Tamilnadu, India
}

\begin{abstract}
Concrete has an excellent intrinsic behaviour when exposed to fire, but a proper thermally enhanced structure design is needed. In recent years, a lot of research is carried out with the addition of nano materials in concrete structure to improve the physical properties and thermal properties. Thermal energy storage (TES) systems using phase change material (PCM) have been recognized as one of the most advanced energy technologies in enhancing the energy efficiency and sustainability of buildings. Nano encapsulation is the method of encapsulating phase change material with shell material such as melamine-formaldehyde or PMMA by using in-situ polymerization technique. Thermal conductivity of shell material found to have a significant influence on the heat exchange between the PCM and heat transfer fluid (HTF). Nano encapsulated material will be characterized using Scanning Electron Microscope (SEM), Transmission Electron Microscope (TEM) and the thermal stability of the material will be analysed using Differential Scanning Calorimetry (DSC) and Thermogravimetric Analyzer (TGA). This paper also reviews the solidification and melting characteristics of the PCM and the effect of various encapsulation parameters on the phase change behaviour.
\end{abstract}

Keywords: Phase change material, Latent Heat storage, Encapsulation, Concrete, Thermal Behaviour

\section{INTRODUCTION}

Phase change material are the material which have property of thermal energy storage, high heat of fusion, melt and solidify at a specific temperature, and are capable of storing and realising thermal energy. Heat energy is absorbed or released when the material change from the solid state to liquid state or vice versa. The heat energy is absorbed during the melting process of phase change material when compared with normal material and a greater amount of energy is absorbed when PCMs melts. The melting points of PCMs are depending on latent heat of storage of the unique materials. The materials will absorb the heat till it changes its phase. There is a continuation in absorption of heat without a significant rise with temperature until all PCMs materials are transformed to the liquefied phase. Whenever temperature of the material falls, then the PCMs released the stored latent heat.

There are different types phase change materials for thermal energy storage in buildings. Generally phase change materials are classified in to two types they are organic and inorganic. But in building applications organic materials is suitable, because inorganic materials have a property of corrosiveness. So, organic material has good impact over the concrete. The organic materials includes butyl stearate (BS), 1-Dodecanol (DD), Polyethylene glycol (peg), 1- tetradecanol (td) and dimethyl sulfoxide. N-octadecane. However, inorganic PCMs suffer from decomposition, subcooling and corrosiveness.

The phase transition occurs during absorption and liberation of heat is shown below in the phase change material. Some of the properties of organic materials are change in volume in during phase transition, materials are chemically stable, non-corrosive, repeatability of phase change, non-toxic, non-flammable, reliability and availability. 


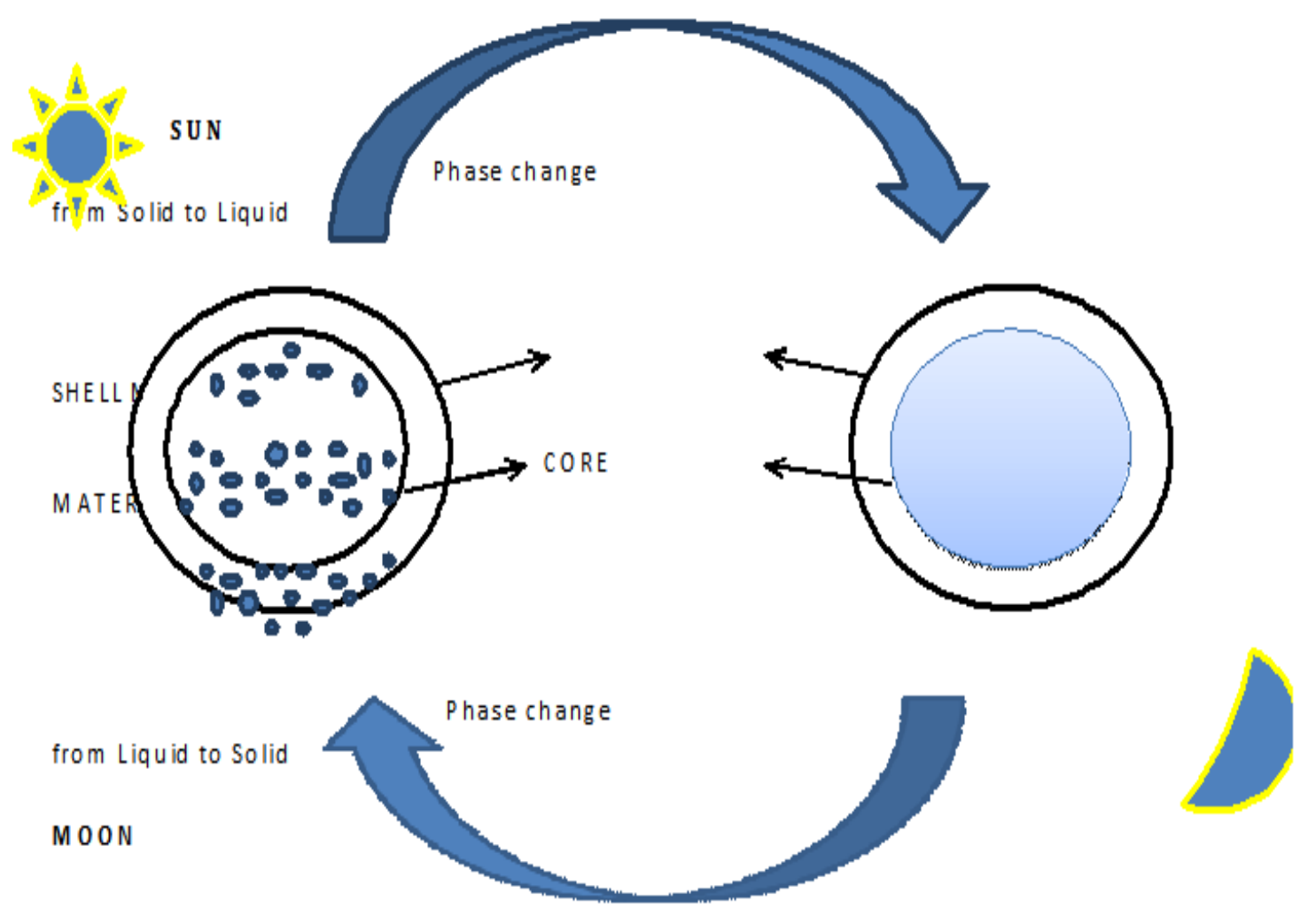

Fig1: Phase change process of phase change material

Nano encapsulation is a process of enclosing nano-sized particles within solid or liquid state, then the product obtained by the process are called nano capsules or nanoparticles. The term nano capsules is used if the size of the particles is below $1 \mu \mathrm{m}$. Recently, Nanocapsules have received considerable attention for thermal energy storage systems, because of the high surface area to volume ratio compared to micro capsules which results in a stronger driving force to increase the thermodynamic process.

\section{LITERATURE REVIEW}

Hydrated salt is common material in inorganic phase change material and it has good impact over building applications but due some limitations such as corrosiveness, very high volume change, super cooling characteristic during phase transition and also at liquid state the PCMs goes beyond its freezing temperature then remaining liquid makes the phase change ineffective, so it will not an suitable for concrete applications [2].

The maximum temperature of the concrete structure with PCMs is shown latter then 2 hours of without PCMs structure and it means that higher in thermal inertia of the wall. The applied encapsulated PCMs and without PCMs in the concrete structure shows that enhance the thermal inertia and as well as inner temperature [4].

The integration of phase change materials in to concrete is three methods they are direct mixing, immersion, and impregnation. Direct mixing is simple method but at the time mixing the shell material should not be destructible and also to ensure that there is no leakage in the phase change material.in this method encapsulated PCMs is used for its stability as well as physical and chemical. Immersion type is normally soaking the concrete structure in to liquid phase change materials. The effectiveness of PCMs is based on the absorption of PCMs in to concrete through porous structure.in this method it will take several hours for absorption. Impregnation is the sensitive technique that is the aggregates of concrete material should be making in to dried condition and soaked with liquid phase change material mixed and then made as a concrete structure [2].

The integration of phase change materials increases in concrete structure means then compression strength of the material decreases. The density of PCMs are lower than the concrete aggregates so, there is a chance to accumulate the PCMs over concrete structure after integrating in to it. There is a decrease in deformation capacity and as well as cohesion and viscosity of the concrete. Compression strength of PCMs with concrete structure increases based on the number days it cured [1].

There is low thermal diffusivity then heats from the solidified PCMs will not provide its effect throughout the entire structure. But as per the process the thermal diffusivity should balance by the spatial distribution. Comparatively the light weighted aggregates mixture has low compressive strength. Whenever the temperature falls then the PCMs undergoes exothermic solidification reaction. The solidifying and freezing is based on the latent heat of fusion of phase change materials [3]. 


\section{OBJECTIVE OF THIS STUDY}

To make comfort room temperature in buildings and reduce the utilization of air conditioning system in buildings, the phase change materials play the efficient role in controlling of temperature. And now a day's utilization of energy factor for operation of air conditioning system is comparatively high. Based on the selection of phase change material the temperature will be controlled in the buildings and here an organic phase change material is incorporated in to concrete and also there is reduction in temperature.

\section{METHODOLOGY}

\subsection{Nanoencapsulation}

The preparation of phase change material size has two types. The preferred process is Nanoencapsulation method. The phase change material has two layers that are the outer layer is shell material and the inner are core material. The shell material plays major role in phase change process. It avoid the leakage of PCMs during the phase change transition occurs. The temperature rise beyond the melting point of core materials then phase transition occurs. The material transform from solid state to liquid state and temperature falls downs means then vice-versa. This type of capsules have received considerable attention for thermal energy storage systems, this is due to high surface area to volume ratio compared to micro capsules which results in a stronger driving force to increase the thermodynamic process.

\subsection{Direct Mixing Method}

The selected method for incorporation of phase change materials into concrete and type concrete mixture are direct mixing method and M20 concrete mix. The nanoencapsulation of PCMs method is polymerization method and most important thing is during the incorporation of PCMs the shell material should not be damage or rupture and this to be taken care off. The PCMs mixing with concrete is in liquid state and not allow flowing down from the concrete layer. The mixing proportion layer of concrete is 3 inch from down out of 4 inches i.e. is 1 inch below from the top of the concrete layer. For this method the shell material have such a hardness for indestructible and to sustain to avoid such a breakage during the mixing process. After applying the phase change materials over the concrete and make one more layer of concrete over the applied PCMs. Then have to put the concrete in curing process.

\section{RESULT AND DISCUSSIONS}

In most of the areas concrete is used for building construction. This concrete structure has capacity to store energy during day time and releasing at night time. Now here modifying the storing and realising of heat energy by addition of phase change material. Incorporation of phase change material in concrete structure has different process. Direct mixing is one of the processes for mixing of phase change materials in to the concrete structure. During this process the incorporation of phase change materials should be sensitive because at that time the shell of encapsulated Phase change materials should not be break up.

The structure of concrete is stressed when it exposed to heat and this stress is based on the number of thermal cycles. One thermal cycle of heating period is 8 hours and subsequent cooling period is 16 hours. Concrete is an organic material than the high temperature and its duration decreases the concrete strength and its durability. The aggregates which involve in the concrete structure are an important factor for thermal properties of the structure. Concrete and cement mortars are under long term exposure in hot weather condition then there is degradation in their properties [5].

The phase change materials which were chosen for incorporation in concrete is Nonadecane. It is an organic phase change material and does not support for the corrosion properties and this material prepared by the polymerisation technique. The core material is nonadecane and shell material is urea-formaldehyde. This shell material plays a major role in this phase change process, because at the time of liquefies the shell material will not allow the core material to leak. The core material has the melting point of around $30-34^{\circ} \mathrm{C}$ and the degradation of phase change material will initiate from $100^{\circ} \mathrm{C}$ and $97 \%$ of the core materiel is degraded at $600^{\circ} \mathrm{C}$.

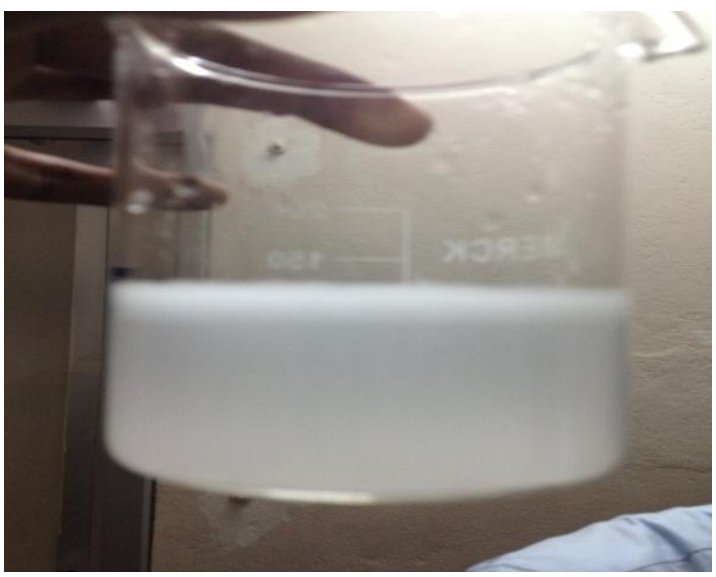

Fig 2: Shows the prepared solution of phase change material i.e. Nonadecane

\subsection{M20 Concrete}

The concrete designed for incorporation of phase change material is M20 concrete type. As per the concrete mixing proportioning standards of IS10262:2009 i.e., Bureau of Indian Standards (BIS) the M20 concrete was designed. The designed size of M20 concrete structure is 24 " $\times 12$ " $\times 4$ " and the aggregates used for designing the concrete structure are coarse aggregates, fine aggregates, water and cement. The mixing proportions of M20 concrete design is 1:1.5:3 and $\mathrm{w} / \mathrm{c}$ ratio is 0.5 . The size of the coarse aggregate is $20 \mathrm{~mm}$.

Table 1: Proportion of concrete material

\begin{tabular}{|l|l|l|}
\hline S.No & Materials & Weight \\
\hline 1. & Cement & $5.48 \mathrm{~kg}$ \\
\hline 2. & Water & $2.74 \mathrm{~kg}$ \\
\hline 3. & Coarse & $19.45 \mathrm{~kg}$ \\
\hline
\end{tabular}




\begin{tabular}{|l|l|l|}
\hline & Aggregates & \\
\hline 4. & $\begin{array}{l}\text { Fine } \\
\text { Aggregates }\end{array}$ & $13.15 \mathrm{~kg}$ \\
\hline
\end{tabular}

Based on the standards of IS10262:2009 and its proportions the design was created. The designed concrete was cured for 28 days [6].

\subsection{Testing of Concrete}

Designed concrete are two types they are normal M20 type concrete and PCM incorporated M20 type concrete. Both concrete are treated equally and tests were taken. The test was taken based on applying various temperatures on both the concrete. During testing, temperature on both concrete is applied equally and output temperature on interior side is varied compared to normal and PCM incorporated concrete. From the testing there is a drop in temperature on PCM incorporated concrete compared to normal concrete.

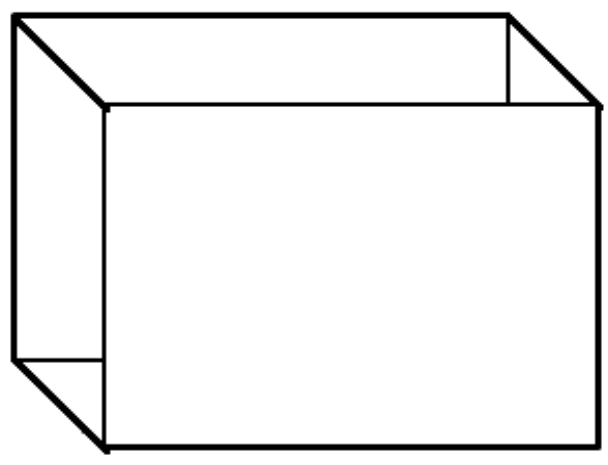

Fig 3: Normal Concrete

Length $=24$ "

Breadth $=12 "$

Thickness $=4 "$

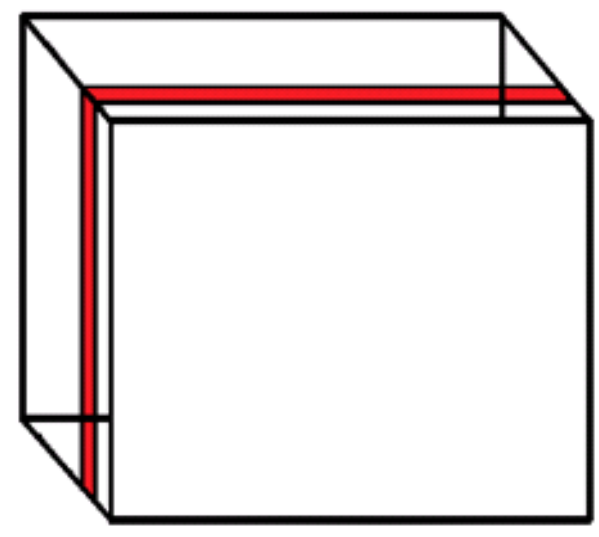

Fig 4: PCM Incorporated Concrete

Length $=24$ "

Breadth $=12 "$

Thickness $=4$ "

I Incorporated PCM
The temperature on both concrete is applied constantly and maximum drop in temperature on incorporated PCM concrete is $5.7^{\circ} \mathrm{C}$. Totally 8 test was taken on various temperatures from $30^{\circ} \mathrm{C}$ to $44^{\circ} \mathrm{C}$. The melting point of nonadecane is around $30^{\circ} \mathrm{C}$. whenever there is elevating in temperature above $30^{\circ} \mathrm{C}$ then there will be drop in temperature due to phase transition occurs on the core material.

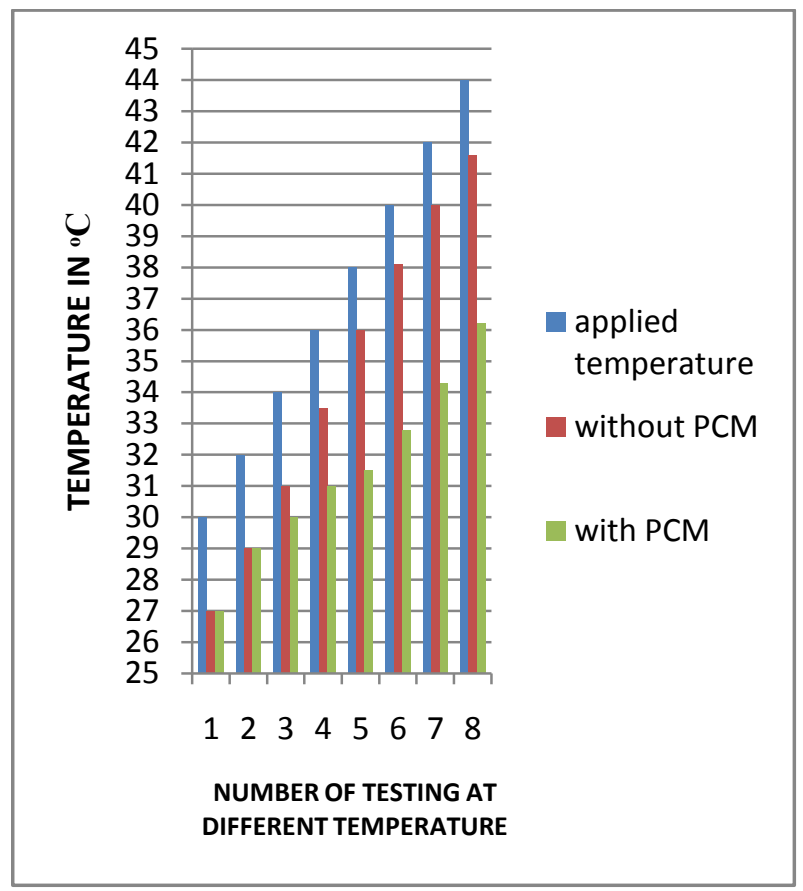

Chart 1: Temperature of normal and PCM incorporated concrete

During this phase transition the heat energy will be absorbed, so drop in temperature occurs.

\section{CONCLUSIONS}

From the following the various testing and results were taken and the efficiency of phase change material clearly known. The core material of phase change material which was incorporated in concrete was efficiently working and there is drop in temperature maximum around $5.7^{\circ} \mathrm{C}$. This help us to reducing the utilization of air conditioning system. Due to incorporation of this organic phase change material the thermal behaviour of the concrete structure was increased. While starting the test on designed structure there is small reduction in temperature drop and the level it goes beyond the melting point of specific PCM, temperature drop is increased. Further, if various percentage on incorporation of PCM in concrete may have a chance to increase the efficiency of the concrete.

\section{REFERENCES}

[1]. María Fenollera , José Luis Míguez , Itziar Goicoechea , Jaime Lorenzo and Miguel Ángel Álvarez The Influence of Phase Change Materials on the Properties of SelfCompacting Concrete, Materials 2013, 6, 3530-3546 www.mdpi.com/journal/materials 
[2]. Tung-Chai Ling, and Chi-Sun Poon Use of phase change materials for thermal energy storage in concrete:An overview, Construction and Building Materials; 46: 5562,2013

[3]. A.R. Sakulich and D.P. Bentz Incorporation of Phase Change Materials in Cementitious Systems via Fine Lightweight Aggregate, Construction and Building Materials, Vol. 35, 483-490, 2012.

[4]. C. Castellón, M. Nogués, J. Roca, M. Medrano, L. F. Cabeza MICROENCAPSULATED PHASE CHANGE MATERIALS (PCM) FOR BUILDING APPLICATIONS

[5]. K. Chandramouli, P. Srinivasa Rao, T. Seshadri Sekhar, N. Pannirselvam and P. Sravana Effect of Thermal Cycles on Compressive Strength of Different Grades of Concrete [6]. M.C. Nataraja and Lelin Das Concrete mix proportioning as per IS 10262:2009 - Comparison with IS 10262:1982 and ACI 211.1-91, The IndIan Concrete Journal SEPTEMBER 2010 